\title{
Editorial
}

\section{Dry Skin and the Environment}

\author{
Joachim W. Fluhr \\ Department of Dermatology, Friedrich Schiller University, Jena, Germany
}

It is well documented that climatic changes influence skin conditions, e.g. epidermal structure and functions. A dry environment for example has an impact on epidermal parameters [1]. Improvement of the stratum corneum (SC) homeostasis can ameliorate skin damage induced by barrier disruption in a dry environment [2]. Furthermore, a dry environment directly increases the epidermal level of pro-inflammatory cytokines [3]. Thus, epidermal homeostasis is very vulnerable when exposed to dry environmental conditions. Histamine $\mathrm{H}_{1}$ and $\mathrm{H}_{2}$ receptor antagonists accelerate skin barrier repair and prevent epidermal hyperplasia induced by barrier disruption in a dry environment [4]. Furthermore, a dry environment increases the epidermal mast cell number and histamine content [5]. A recent publication showed the modulation of gene expression induced in human epidermis by environmental stress [6]: the authors could show a general overexpression of MRP8 and MRP14 (both members of the S100 family) as markers for stressed skin being involved in epidermal repair pathways. Loeffler and Happle [7] reported an increased susceptibility against irritant patch tests during cold climatic conditions during winter and spring. The climatic impact on epidermal functions could be prevented with the application of a moisturizing cream [8]. The daily treatment is effective in improving mild subclinical inflammation that is induced on the facial skin by the winter environment [8].
On the other hand, an increase in environmental humidity also induced abnormalities in permeability homeostasis [9].

In this issue of Exogenous Dermatology, environmental factors on dry skin are discussed by five distinguished experts (or their groups) in this field:

Wertz (this issue) gives an integrated overview of the epidermal barrier function and their regional variations. His contribution focuses on lipids of the SC and the relationship of SC hydration and barrier function. Furthermore, the pathophysiological aspects of hyperproliferative epidermal conditions with a decreased SC water content, increased transepidermal water loss and an altered skin surface are discussed.

Rawlings (this issue) reports about water and SC biomechanics. The state of SC hydration depends on the supplied water from deeper parts of the skin, the evaporation rate at the surface and the water-binding capacity of the SC. The desquamation and proliferation process is highly dependent on both enzyme activity and the integrity of the intercellular lipid matrix. At high humidity, the epidermal synthesis of lipids and natural moisturizing factor is switched off. The reduction in natural moisturizing factor levels together with lipid composition induces changes in the water content in the different layers of the SC. Subsequently this leads to local secretion of proinflammatory cytokines that can, either directly or indi-

\section{KARGER \\ Fax +4161306 1234 E-Mail karger@karger.ch} www.karger.com
C 2004 S. Karger AG, Basel 1424-4616/04/0032-0051\$21.00/0

www.karger.com/exd
Joachim W. Fluhr

Head of Skin Physiology Laboratory, Department of Dermatology

Friedrich Schiller University Jena, Erfurter Strasse 35

DE-07743 Jena (Germany)

E-Mail fluhr@derma.uni-jena.de 
rectly, lead to keratinocyte hyperproliferation and pathological desquamation. Clinically this might result in sensations of tightness and itchiness and subsequent induction of pruritus. In the state of dry skin, the metabolism of filaggrin is reduced and consequently reduces natural moisturizing factor.

In their review, Mac-Mary et al. (this issue) discuss the influence of seasonal changes on skin properties. Low relative humidity together with low temperatures plays a fundamental role in winter xerosis. These phenomena are intensified with skin aging and can be aggravated by lifestyle and working conditions.

Imokawa (this issue) shows that the ceramide content in the SC is associated with regulation of SC hydration. The use of surfactant induces a reduced SC hydration based on decreased ceramides. This publication describes the physicochemical factors associated with the water-holding capacity of the SC and the underlying mechanisms of surfactant-induced dehydration. Synthetic pseudoceramides are effective in preventing dehydration and thus the tight sensation and roughness of the skin.
Lodén et al. (this issue) report on eczema and other dry skin conditions where moisturizers are commonly used. Moisturizers have been found to change skin barrier function, and it appears that certain combinations of ingredients increase skin susceptibility to external agents. Treatment with a urea cream reduced transepidermal water loss. However, the susceptibility to nickel sulphate was not changed by the treatment. The authors suggest that the absence of a correlation between transepidermal water loss and skin susceptibility to nickel is based on different penetration pathways of water and nickel through the skin.

This issue of Exogenous Dermatology provides evidence that the maintenance of an equilibrium of SC hydration and epidermal barrier function is of the outmost importance for the homeostasis of the epidermis under different climatic conditions during different seasons. Consequently, a single moisturizer formulation might not be sufficient to stabilize a vulnerable skin, e.g. in atopic dermatitis, throughout the entire year with different climatic conditions (i.e. room temperature, outdoor temperature and relative humidity both outside and inside buildings).

\section{References}

1 Denda M, Sato J, Masuda Y, Tsuchiya T, Koyama J, Kuramoto M, Elias PM, Feingold KR: Exposure to a dry environment enhances epidermal permeability barrier function. J Invest Dermatol 1998;111:858-863.

2 Denda M: Influence of dry environment on epidermal function. J Dermatol Sci 2000; 24(suppl 1):S22-S28.

3 Ashida Y, Ogo M, Denda M: Epidermal interleukin-1 alpha generation is amplified at low humidity: Implications for the pathogenesis of inflammatory dermatoses. $\mathrm{Br} \mathrm{J}$ Dermatol 2001;144:238-243.
4 Ashida Y, Denda M, Hirao T: Histamine $\mathrm{H}_{1}$ and $\mathrm{H}_{2}$ receptor antagonists accelerate skin barrier repair and prevent epidermal hyperplasia induced by barrier disruption in a dry environment. J Invest Dermatol 2001;116:261265.

5 Ashida Y, Denda M: Dry environment increases mast cell number and histamine content in dermis in hairless mice. Br J Dermatol 2003; 149:240-247.

6 Marionnet C, Bernerd F, Dumas A, Verrecchia F, Mollier K, Compan D, Bernard B, Lahfa M, Leclaire J, Medaisko C, Mehul B, Seite S, Mauviel A, Dubertret L: Modulation of gene expression induced in human epidermis by environmental stress in vivo. J Invest Dermatol 2003;121:1447-1458.
7 Loeffler H, Happle R: Influence of climatic conditions on the irritant patch test with sodium lauryl sulphate. Acta Derm Venereol 2003;83:338-341.

8 Kikuchi K, Kobayashi H, Hirao T, Ito A, Takahashi $\mathrm{H}$, Tagami H: Improvement of mild inflammatory changes of the facial skin induced by winter environment with daily applications of a moisturizing cream: A half-side test of biophysical skin parameters, cytokine expression pattern and the formation of cornified envelope. Dermatology 2003;207:269-275.

9 Sato J, Denda M, Chang S, Elias PM, Feingold KR: Abrupt decreases in environmental humidity induce abnormalities in permeability barrier homeostasis. J Invest Dermatol 2002; 119:900-904. 